\title{
WILEY-VCH
}

\section{Use of Hydrogen Molybdenum Bronze in Vacuum-Deposited Perovskite Solar Cells}

Kassio P. S. Zanoni*, Daniel Pérez-del-Rey, Chris Dreessen, $M^{a}$ Angeles Hernández-Fenollosa, Andrea S. S. de Camargo, Michele Sessolo, Pablo P. Boix*, Henk J. Bolink

Dr. K. P. S. Zanoni, Daniel Pérez-del-Rey, Chris Dreessen, Dr. Michele Sessolo, Dr. Pablo P. Boix, Dr. Henk J. Bolink

Molecular Opto-Electronic Devices (MOED), Instituto de Ciencia Molecular, Universidad de Valencia, C/ Catedrático J. Beltrán 2, 46980 Paterna, Spain.

E-mail: zanoni@ifsc.usp.br; pablo.p.boix@uv.es.

Prof. M Angeles Hernández-Fenollosa

Instituto de Tecnología de Materiales, Universitat Politècnica de Valencia, Camino de Vera s/n, Valencia 46022, Spain

Prof. Andrea S. S. de Camargo

Laboratory of Spectroscopy of Functional Materials (LEMAF), Instituto de Física de São Carlos, Universidade de São Paulo, Av. Trabalhador Sãocarlense 400, 13566-590 São Carlos, Brazil.

Keywords: perovskite solar cell, hydrogen molybdenum bronze, molybdenum oxide

In this work, the dehydration of a hydrogen molybdenum bronze $\left(\mathrm{HYMoO}_{3}\right)$, converting it to molybdenum oxide $\left(\mathrm{MoO}_{\mathrm{x}}\right)$, is explored towards the development of perovskite solar cells for the first time. $\mathrm{H}_{0.11} \mathrm{MoO}_{3}$ bronze is synthesized, characterized and deposited on ITO under different concentrations and annealing conditions for the in-situ conversion into $\mathrm{MoO}_{\mathrm{X}}$ with appropriate oxygen vacancies. Vacuum-deposited perovskite solar cells are fabricated using the as-produced $\mathrm{MoO}_{\mathrm{X}}$ hole injection layers, achieving a power conversion efficiency of 17.3\% (average) for the optimal device. The later has its stability and reproducibility tested, proving the robustness and affordability of the developed hole transport layer in perovskite solar cells.

In perovskite solar cells (PSCs), an efficient extraction of photogenerated chargecarriers to the appropriate electrode requires the use of efficient selective charge transport layers in the device configuration. Molybdenum (VI) oxide $\left(\mathrm{MoO}_{3}\right)$ is a recurrently used hole transport 


\section{WILEY-VCH}

layer (HTL) in organic, quantum dot and perovskite solar cells, as it has a low-lying conduction band with a very deep work function, forms an optimal ohmic contact with ITO, and provides higher stability than usual organic layers. ${ }^{[1-4]}$ Hydrogen molybdenum bronzes $\left(\mathrm{HYMoO}_{3}\right)$ are $\mathrm{MoO}_{3}$ reciprocals having small amounts of hydroxide groups replacing some of the oxygen atoms ${ }^{[5-8]}$ that can be converted to $\mathrm{MoO}_{\mathrm{x}}\left(\mathrm{MoO}_{3}\right.$ with proper amounts of oxygen vacancies to improve ohmic contact and conduction ${ }^{[9]}$ ) through dehydration via heating or vacuum treatment. ${ }^{[10-13]}$ In particular, $\mathrm{H}_{\mathrm{Y} M o O}$-based HTLs has been proven suitable for the processing of organic and silicon solar cells as well as in ion storage systems; ${ }^{[14-20]}$ however, to the best of our knowledge, it has never been explored in PSCs to date. In this communication, the in-situ $\mathrm{H}_{\mathrm{Y}} \mathrm{MoO}_{3}-\mathrm{to}-\mathrm{MoO}_{\mathrm{X}}$ conversion on top of ITO is explored for the first time as an efficient HTL in vacuum-deposited PSCs, specially aiming at the optimal conditions for reproducibility and more-affordable production processes.

Mixing Mo metal powder with $\mathrm{H}_{2} \mathrm{O}_{2}$ in ethanol led to the formation of dark blue $\mathrm{H}_{\mathrm{YMoO}}$ (the detailed preparation is described in the Supp. Info.). During synthesis, metallic Mo was oxidized by $\mathrm{H}_{2} \mathrm{O}_{2}$ into Mo-peroxides, while ethanol provided both electrons and protons to the reduction of Mo-peroxide into $\mathrm{MoO}_{3}$ and to the insertion of $\mathrm{H}^{+}$into the $\mathrm{MoO}_{3}$ lattice, producing $\mathrm{OH}$ and $\mathrm{Mo}^{\mathrm{V}}$ sites. ${ }^{[7,15]}$ The final product was re-dissolved in isopropanol solutions, exhibiting a dark blue tone with the molar extinction coefficient displayed in Figure 1A. Analysis by X-ray photoelectron spectroscopy (XPS) of the Mo $3 d_{3 / 2}-3 d_{5 / 2}$ doublets (Figure 1B) reveals a major contribution of $\mathrm{Mo}^{\mathrm{VI}}$ (cyan area in Figure 1B, with peaks at 236.0 and $232.8 \mathrm{eV}$ ) overlapping with the signal of the $\mathrm{Mo}^{\mathrm{V}}$ counterpart (grey area in Figure 1B, with peaks at 231.6 and $234.6 \mathrm{eV}$ ). Based on the observed $3: 25 \mathrm{Mo}^{\mathrm{V}}: \mathrm{Mo}^{\mathrm{VI}}$ molar ratio, the stoichiometric composition of our synthesized bronze is determined as $\mathrm{H}_{0.11} \mathrm{MoO}_{3}$, hence it is classified as Type I ( $\mathrm{H}_{\mathrm{YMoO}} \mathrm{M}_{3}$ with $\mathrm{Y}<0.4$; dark blue; orthorhombic), the most stable form, usually remaining immutable even after months in air. ${ }^{[5,6]}$ 


\section{WILEY-VCH}

In order to evaluate the $\mathrm{H}_{0.11} \mathrm{MoO}_{3}$ suitability as a precursor for $\mathrm{MoO}_{\mathrm{X}}-\mathrm{HTL}$ in PSCs, the solutions were deposited onto pre-patterned ITO by spin-coating, then annealed at $100{ }^{\circ} \mathrm{C}$ (in air or in $\left.\mathrm{N}_{2}\right)$ and inserted in an evaporator, where vacuum $\left(10^{-6} \mathrm{mbar}\right)$ is achieved and maintained for 10 min prior to vacuum-deposition of the subsequent layers. Dehydration of $\mathrm{H}_{0.11} \mathrm{MoO}_{3}$ can take place during the annealing and vacuum treatments, resulting in its conversion to $\mathrm{MoO}_{\mathrm{X}} \cdot{ }^{[10-13]}$ For example, for $1 \mathrm{~g} \mathrm{~mL}^{-1}$ samples that were annealed in $\mathrm{N}_{2}$ followed by the above mentioned vacuum treatment, XPS (Figure 1C) revealed a $\mathrm{Mo}^{\mathrm{V}}: \mathrm{Mo}^{\mathrm{VI}}$ molar ratio of 3:50, thus a stoichiometry of $\mathrm{MoO}_{2.94}$. The $\mathrm{MoO}_{2.94}$ film is $15-20 \mathrm{~nm}$ thick and has a very uniform and smooth surface with root mean-square roughness $\left(r_{\mathrm{q}}\right)$ and waviness $\left(w_{\mathrm{q}}\right)$ of $0.36 \pm$ $0.02 \mathrm{~nm}$ and $0.68 \pm 0.08 \mathrm{~nm}$, respectively, as proven by atomic force microscopy (AFM) (Figure 1E). Thus, the $\mathrm{MoO}_{2.94}$ surface is flatter than the ITO underneath (Figure 1D; $r_{\mathrm{q}}=1.08$ $\pm 0.05 \mathrm{~nm} ; w_{\mathrm{q}}=1.42 \pm 0.29 \mathrm{~nm}$ ) or the usually rough films spin-coated from $\mathrm{MoO}_{3}$ nanoparticle solutions $\left(r_{\mathrm{q}} \sim 15-30 \mathrm{~nm}^{[15]}\right)$. Scanning electron microscopy images of the $\mathrm{MoO}_{2.94}$ surface and the energy-dispersive X-ray spectrum are exhibited in Figure S1 and S2 in the Supp. Info., confirming traces of Mo on the surface of (glass/)ITO. Additionally, the obtained $\mathrm{MoO}_{2.94}$ is practically transparent in the wavelength range where the perovskite semiconductor absorbs sunlight, apart from a low scattering in the red (Figure S3 in the Supp. Info.). Finally, as reported by Birtill and Dickens, ${ }^{[6]}$ polycrystalline powders of both the $\mathrm{H}_{0.11} \mathrm{MoO}_{3}$ bronze and the $\mathrm{MoO}_{2.94}$ oxide present the orthorhombic lattice structure (the most stable crystalline structure). For thin films of these materials, however, no signals were observed in X-ray diffraction (XRD) analyses (Figure S4 in the Supp. Info).

The as-prepared ITO/MoOx substrates were employed in ITO/MoOx(15 nm)/TaTm(10 $\mathrm{nm}) / \mathrm{CH}_{3} \mathrm{NH}_{3} \mathrm{PbI}_{3}(560 \mathrm{~nm}) / \mathrm{C}_{60}(25 \mathrm{~nm}) / \mathrm{BCP}(7 \mathrm{~nm}) / \mathrm{Ag}$ devices, in which all the subsequent layers $\left(\mathrm{TaTm}=\mathrm{N} 4, \mathrm{~N} 4, \mathrm{~N} 4{ }^{\prime \prime}, \mathrm{N} 4{ }^{\prime \prime}\right.$-tetra([1,1'-biphenyl]-4-yl)-[1,1':4',1"-terphenyl]-4,4"diamine; $\mathrm{C}_{60}=$ fullerene; $\mathrm{BCP}=$ bathocuproine) were vacuum-deposited, including the $\mathrm{CH}_{3} \mathrm{NH}_{3} \mathrm{PbI}_{3}$ perovskite layer, as described in detail in the Supp. Info. This architecture relied 


\section{WILEY-VCH}

on TaTm and $\mathrm{C}_{60}$ as intrinsic organic materials for charge selection, and $\mathrm{MoO}_{\mathrm{X}}$ and $\mathrm{BCP}$ as charge transport layers for efficient extraction of the photogenerated holes and electrons, respectively. ${ }^{[4,21]}$

As summarized in Table S1 and Figure S5 in the Supp. Info., the optimal $\mathrm{H}_{0.11} \mathrm{MoO}_{3}$ concentration leading to the best device performances was $1 \mathrm{~g} \mathrm{~mL}^{-1}$. For a non-annealed $\mathrm{H}_{0.11} \mathrm{MoO}_{3}$ sample, with conversion to $\mathrm{MoO}_{\mathrm{x}}$ proceeding only through the vacuum treatment, an inferior PCE of $14.5 \%$ under AM1.5G illumination was observed mainly due to a lower FF; nevertheless, the non-annealed vacuum-treated $\mathrm{MoO}_{\mathrm{X}}$ can be strategical for the future development of flexible devices using malleable substrates that require low temperature processing. Annealing in air led to a PCE of $16 \%$, while annealing in $\mathrm{N}_{2}$ inside of a glovebox (leading to the $\mathrm{MoO}_{2.94}$ layer described above) yielded improvements in every photovoltaic parameters, reaching a PCE of $17.3 \%$ (average). To identify the origin of the different performances of air vs nitrogen annealed MoOx films, we determined their work function (WF) and found values of 5.7 and $5.5 \mathrm{eV}$ for the air and $\mathrm{N}_{2}$ annealed films, respectively. Air exposure during annealing (with high concentrations of $\mathrm{O}_{2}$ and other adsorbates such as water) hampered the oxygen vacancy generation, leading to a less effective n-type doping in line with the observed higher WF, which in turn can result in a small energetic off set to the TaTm (for air annealed films) hence in a lower FF.

As depicted in Figure 2A, the average $J-V$ curve of the optimal device based on $\mathrm{MoO}_{2.94}$ ( $1 \mathrm{~g} \mathrm{~mL}^{-1} \mathrm{H}_{0.11} \mathrm{MoO}_{3}$ solution annealed for $10 \mathrm{~min}$ in $\mathrm{N}_{2}$ followed by vacuum treatment) was not affected by hysteresis, with $J_{\mathrm{SC}}, V_{\mathrm{OC}}$ and $F F$ of $20.3 \pm 0.01 \mathrm{~mA} \mathrm{~cm}^{-2}, 1.130 \pm 0.006 \mathrm{~V}$ and $75.5 \pm 0.7 \%$, respectively, resulting in a PCE of $17.3 \pm 0.1 \%$ (as summarized in Table 1 ). The statistics of 20 devices are exhibited in Figure $2 \mathbf{B}$ (while $J_{\mathrm{SC}}, V_{\mathrm{OC}}$ and FF statistics are shown in Figure S6 in the Supp. Info.), with excellent reproducibility; a maximum efficiency of $17.43 \%$ was observed for the best solar cell. 


\section{WILEY-VCH}

Recently, we have shown the use of vacuum-deposited $\mathrm{MoO}_{\mathrm{x}}$ layers in p-i-n and n-i-p perovskite solar cells. $^{[22]}$ Table 1 compares the photovoltaic performances of ITO/MoOX/TaTm/ $\mathrm{CH}_{3} \mathrm{NH}_{3} \mathrm{PbI}_{3} / \mathrm{C}_{60} / \mathrm{BCP} / \mathrm{Ag}$ solar cells having a $\mathrm{H}_{0.11} \mathrm{MoO}_{3}$-solutionprocessed or a vacuum-deposited $\mathrm{MoO}_{\mathrm{X}}$ layer (both sets having the same evaporation batch for $\mathrm{TaTm} / \mathrm{CH}_{3} \mathrm{NH}_{3} \mathrm{PbI}_{3} / \mathrm{C}_{60} / \mathrm{BCP} / \mathrm{Ag}$ layers on top of $\mathrm{MoO}_{\mathrm{X}}$; average of at least 20 samples). While $J_{\mathrm{SC}}$ was the same for both architectures, the solution processed sample showed an slightly improved $V_{\text {OC }}$, suggesting lower non-radiative recombination losses. However, there was an accentuated decrease in the $\mathrm{FF}$ of $\mathrm{H}_{0.11} \mathrm{MoO}_{3}$-based samples that ultimately led to slightly lower PCEs, indicating the thicker solution-processed $\mathrm{MoO}_{\mathrm{x}}$ layer $(15 \mathrm{~nm})$ suffers from an increased resistivity in comparison to the thinner evaporated layer $(6 \mathrm{~nm})$. Indeed, thinner $\mathrm{MoO}_{\mathrm{X}}$ layers are more easily obtained and controlled by vacuum deposition. The results indicate that a fine tuning of the $\mathrm{H}_{0.11} \mathrm{MoO}_{3}$ solution deposition to produce more compact films (e.g. by adjusting spin-coating‘s RPMs or using other wet deposition techniques) could possibly lead to similar or even higher efficiencies, since $\mathrm{V}_{\mathrm{OC}}$ is actually better for $\mathrm{H}_{0.11} \mathrm{MoO}_{3}$-based devices.

As expected, the $J_{\mathrm{SC}}$ (hence $P C E$ ) was linearly dependent to the light intensity (Figure S7 in the Supp. Info.), which indicates an optimum charge collection under the studied illumination intensities. The plot of $V_{\mathrm{OC}}$ as a function of illumination (Figure 2C) could be fitted by two linear components; at the region with lower charge carrier concentration, an ideality factor of 2.00 was observed, indicating a predominant trap-mediated recombination of charge carriers, while at higher light intensities the ideality factor decreased to 1.33, indicative of direct recombination (probably at the interface). ${ }^{[23]}$

For stability tests, photovoltaic parameters of the encapsulated optimal device were measured every $10 \mathrm{~min}$ in air, with a constant temperature of $300 \mathrm{~K}$ and relative humidity in the 50-70\% range (Figure 2D). The device experienced an increase in $V_{\mathrm{OC}}$ (from 1.130 to 1.167 V) in the first $25 \mathrm{~h}$, when it reached a stable plateau with practically constant values until the end of the measurement $\left(V_{\text {OC }}\right.$ at $\left.t_{80}=1.162 \mathrm{~V}\right)$; the constant $V_{\text {OC }}$ over time is indicative that the 


\section{WILEY-VCH}

$\mathrm{MoO}_{2.94}$ hole transport layer is very stable and not subjected to decomposition. PCE reached $17.9 \%$ in the first hours then $F F, J_{\mathrm{SC}}$ and $P C E$ experienced a quasi-linear decrease (with $t_{80}=$ $117 \mathrm{~h}$ ), due to decomposition of MAPI in air.

In summary, we present a low-cost $\mathrm{H}_{\mathrm{Y}} \mathrm{MoO}_{3}$ precursor to produce a $\mathrm{MoO}$-based hole injection layer on top of ITO for efficient, stable and reproducible vacuum-deposited PSC for the first time. The performances of the so-fabricated solar cells are tunable by the concentration of the spin-castable $\mathrm{H}_{0.11} \mathrm{MoO}_{3}$ solution and subsequent annealing treatments, with efficiencies reaching $~ 18 \%$ for the optimal devices with a $\mathrm{MoO}_{2.94}$ layer. Compared to vacuum-deposited MoOx, the $\mathrm{MoO}_{2.94}$ layer leads to devices with a higher Voc, yet a slightly decreased PCE due to a smaller FF. The $\mathrm{H}_{Y} \mathrm{MoO}_{3}$ film has potential to be doped with different classes of materials, e.g. Ag nanoparticles to improve electrical properties ${ }^{[14]}$ or $\mathrm{Cs}^{+}$cations to tune the work function of the final $\mathrm{MoO}_{\mathrm{X}}$ film ${ }^{[18]}$ (which can potentially lead to the development of n-i-p perovskite solar cells having a $\mathrm{MoO}_{\mathrm{x}}$-based electron transport underlayer), stimulating the investigation of new materials to be used in PSCs. Therefore, $\mathrm{H}_{Y} \mathrm{MoO}_{3}$-based films can certainly benefit investigation groups in the optoelectronics field lacking complex/expensive infrastructures for vacuum-deposition of $\mathrm{MoO}_{\mathrm{x}}$ charge transport layers.

\section{Supporting Information}

Supporting Information is available from the Wiley Online Library or from the author.

\section{Acknowledgments}

Financial support is acknowledged from the Spanish Ministry of Economy and Competitiveness (MINECO) via the Unidad de Excelencia María de Maeztu MDM-2015-0538, MAT201788821-R, PCIN-2015-255, PCIN-2017-014 and the Generalitat Valenciana (Prometeo/2016/135). K.P.S.Z. and A.S.S.C acknowledge the financial support from Fundação de Amparo à Pesquisa do Estado de São Paulo Paulo FAPESP for financing CeRTEV - Center of Research, Technology and Education on Vitreous Materials (2013/07793-6), and a postdoctoral scholarship (2018/05152-7). P.B and M.S. thanks the MINECO for their RyC contracts. P.B. acknowledges the financial support from the Conselleria d'Educació, Investi-gació, Cultura i Esport Valenciana (SEJI2017/2017/012). Special thanks to Dr. Fernando C. Pascual for performing the XPS measurements. 


\section{WILEY-VCH}

Received: ((will be filled in by the editorial staff))

Revised: ((will be filled in by the editorial staff)) Published online: ((will be filled in by the editorial staff))

References

[1] V. Shrotriya, G. Li, Y. Yao, C.-W. Chu, Y. Yang, Appl. Phys. Lett. 2006, 88, 073508.

[2] J. Gao, C. L. Perkins, J. M. Luther, M. C. Hanna, H.-Y. Chen, O. E. Semonin, A. J. Nozik, R. J. Ellingson, M. C. Beard, Nano Lett. 2011, 11, 3263.

[3] J. Meyer, S. Hamwi, M. Kröger, W. Kowalsky, T. Riedl, A. Kahn, Adv. Mater. 2012, $24,5408$.

[4] D. Pérez-del-Rey, L. Gil-Escrig, K. P. S. Zanoni, C. Dreessen, M. Sessolo, P. P. Boix, H. J. Bolink, Chem. Mater. 2019, 10.1021/acs.chemmater.9b01396.

[5] J. J. Birtill, P. G. Dickens, Mater. Res. Bull. 1978, 13, 311.

[6] J. J. Birtill, P. G. Dickens, J. Solid State Chem. 1979, 29, 367.

[7] P. G. Dickens, R. H. Jarman, R. C. T. Slade, C. J. Wright, J. Chem. Phys. 1982, 77, 575.

[8] N. Sotani, K. Eda, M. Sadamatu, S. Takagi, Bull. Chem. Soc. Jpn. 1989, 62, 903.

[9] J. Meyer, R. Khalandovsky, P. Görrn, A. Kahn, Adv. Mater. 2011, 23, 70.

[10] N. Sotani, Y. Kawamoto, M. Inui, Mater. Res. Bull. 1983, 18, 797.

[11] N. Sotani, M. Kunitomo, M. Hasegawa, Chem. Lett. 1983, 12, 647.

[12] N. Sotani, N. Yoshida, Y. Kawamoto, S. Kishimoto, M. Hasegawa, Bull. Chem. Soc. Jpn. 1984, 57, 3032.

[13] N. Sotani, N. Yoshida, Y. Yoshioka, S. Kishimoto, Bull. Chem. Soc. Jpn. 1985, 58, 1626.

[14] X. Li, W. C. H. Choy, F. Xie, S. Zhang, J. Hou, J. Mater. Chem. A 2013, 1, 6614.

[15] F. Xie, W. C. H. Choy, C. Wang, X. Li, S. Zhang, J. Hou, Adv. Mater. 2013, 25, 2051.

[16] A. Soultati, A. M. Douvas, D. G. Georgiadou, L. C. Palilis, T. Bein, J. M. Feckl, S. Gardelis, M. Fakis, S. Kennou, P. Falaras, et al., Adv. Energy Mater. 2014, 4, 1300896. 


\section{WILEY-VCH}

[17] J. Wang, J. Zhang, B. Meng, B. Zhang, Z. Xie, L. Wang, ACS Appl. Mater. Interfaces 2015, 7, 13590 .

[18] X. Li, F. Xie, S. Zhang, J. Hou, W. C. H. Choy, Light Sci. Appl. 2015, 4, e273.

[19] W. J. Dong, J. Ham, G. H. Jung, J. H. Son, J.-L. Lee, J. Mater. Chem. A 2016, 4, 4755.

[20] J. Tong, Y. Wan, J. Cui, S. Lim, N. Song, A. Lennon, Appl. Surf. Sci. 2017, 423, 139.

[21] C. Momblona, L. Gil-Escrig, E. Bandiello, E. M. Hutter, M. Sessolo, K. Lederer, J. Blochwitz-Nimoth, H. J. Bolink, Energy Environ. Sci. 2016, 9, 3456.

[22] D. Pérez-del-Rey, L. Gil-Escrig, K. P. S. Zanoni, C. Dressen, M. Sessolo, P. P.Boix, H. J. Bolink, Chem. Mater. 2019, DOI: 10.1021/acs.chemmater.9b01396

[23] W. Tress, M. Yavari, K. Domanski, P. Yadav, B. Niesen, J. P. Correa Baena, A. Hagfeldt, M. Graetzel, Energy Environ. Sci. 2018, 11, 151. 


\section{WILEY-VCH}
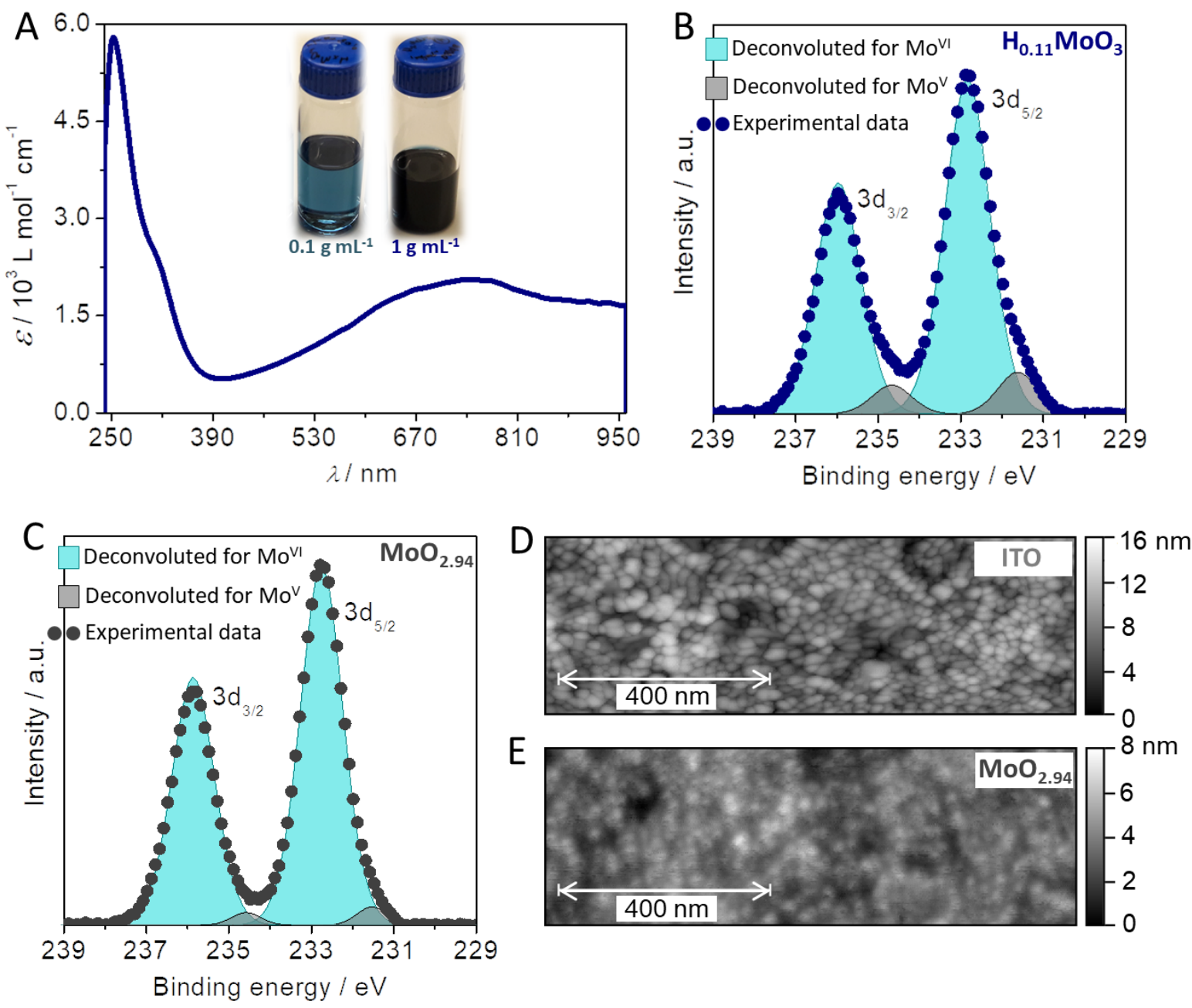

Figure 1. (A) Extinction coefficient spectrum of $\mathrm{H}_{0.11} \mathrm{MoO}_{3}$ in isopropanol. XPS spectra of thin films of (B) $\mathrm{H}_{0.11} \mathrm{MoO}_{3}$ before annealing or (C) $\mathrm{H}_{0.11} \mathrm{MoO}_{3}$ after annealing/vacuum treatment (equivalent to $\mathrm{MoO}_{2.94}$ ) . AFM images of the surface of (D) bare ITO or (E) $\mathrm{MoO}_{2.94}$. 
WILEY-VCH
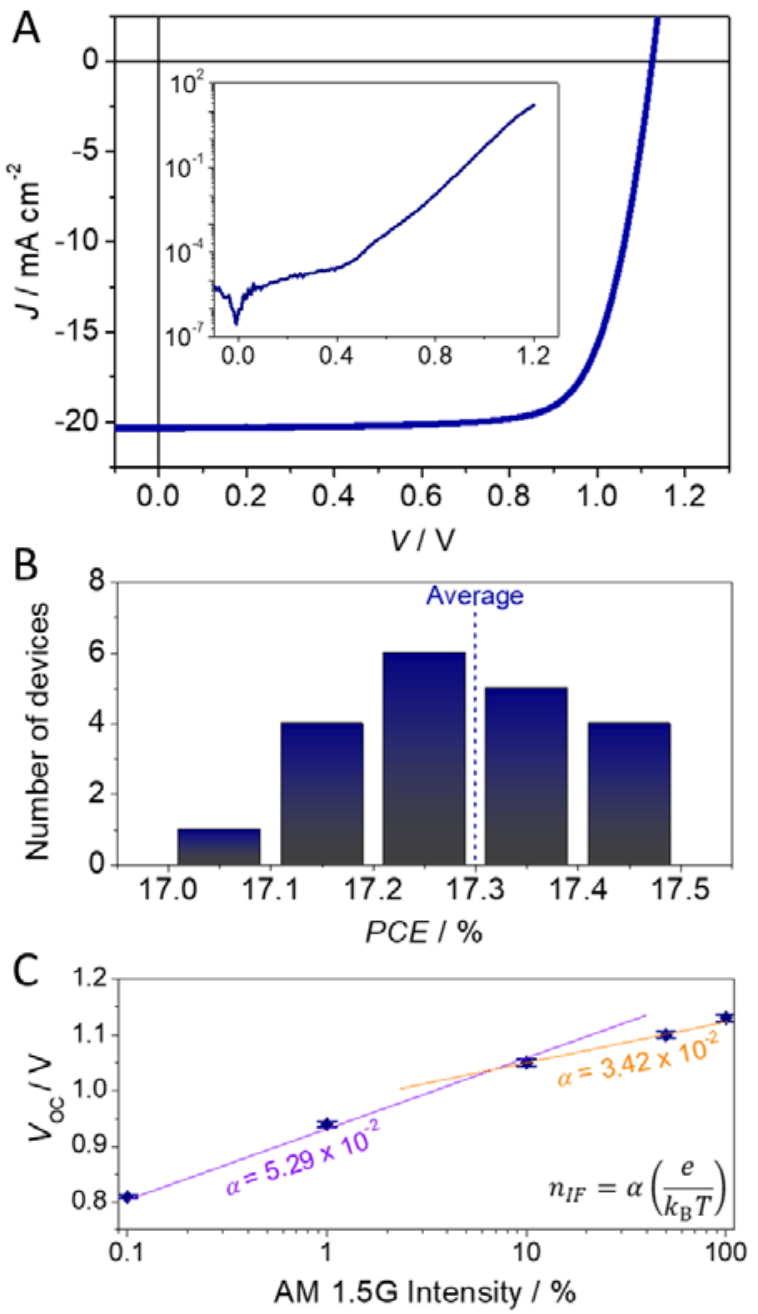

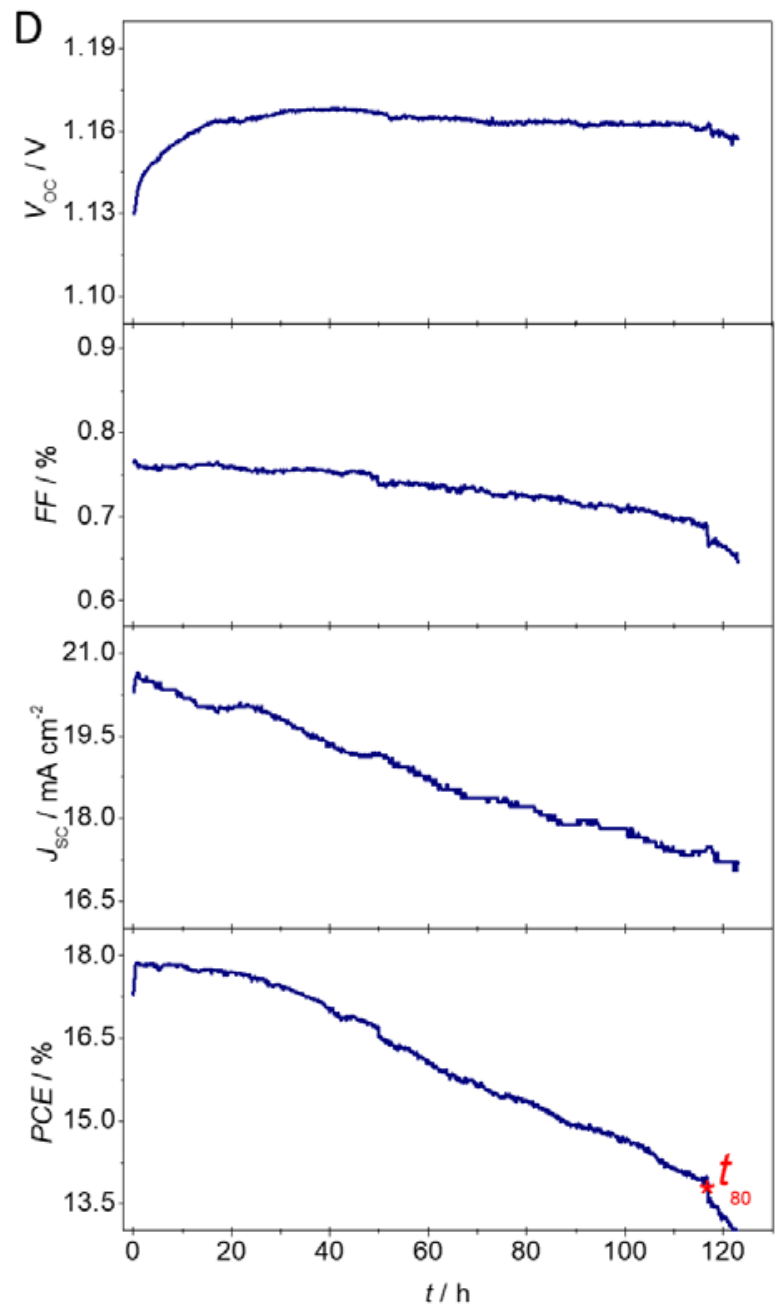

Figure 2. Photovoltaic performance of optimal ITO/MoO ${ }_{2.94} / \mathrm{TaTm} / \mathrm{MAPI} / \mathrm{C}_{60} / \mathrm{BCP} / \mathrm{Ag} \mathrm{PSCs}$. (A) Forward and backward $J-V$ curves, with dark curve as inset. (B) PCE statistical histogram for 20 device samples. (C) Behavior of $V_{\text {OC }}$ versus light intensity. (D) Photovoltaic parameters versus time measured in air (300 K; 50-70\% relative humidity). 


\section{WILEY-VCH}

Table 1. A comparison of the photovoltaic performances of ITO/MoOX/TaTm/ $\mathrm{CH}_{3} \mathrm{NH}_{3} \mathrm{PbI}_{3} / \mathrm{C}_{60} / \mathrm{BCP} / \mathrm{Ag}$ solar cells $\left(0.065 \mathrm{~cm}^{2}\right.$ active area; $0.026 \mathrm{~cm}^{2}$ mask; AM1.5G) having a $\mathrm{H}_{0.11} \mathrm{MoO}_{3}$-solution-processed or a vacuum-deposited $\mathrm{MoO}_{\mathrm{X}}$ layer (both sets having the same evaporation batch for TaTm/ $\mathrm{CH}_{3} \mathrm{NH}_{3} \mathrm{PbI}_{3} / \mathrm{C}_{60} / \mathrm{BCP} / \mathrm{Ag}$ layers on top of $\mathrm{MoO}$; ; average of at least 20 samples).

\begin{tabular}{ccccc}
\hline Sample & $J_{\mathrm{SC}} / \mathbf{m A ~ c m} \mathbf{~ c}^{-2}$ & $V_{\mathrm{OC}} / \mathbf{V}$ & $\boldsymbol{F F} / \%$ & $\boldsymbol{P C E} / \%$ \\
\hline $\mathrm{H}_{0.11 \mathrm{MoO}_{3} \text {-solution-processed }}$ & $20.6 \pm 0.2$ & $1.130 \pm 0.006$ & $75.5 \pm 0.7$ & $17.3 \pm 0.1$ \\
vacuum-deposited & $20.3 \pm 0.1$ & $1.120 \pm 0.006$ & $78.3 \pm 0.2$ & $18.0 \pm 0.2$ \\
\hline
\end{tabular}




\section{WILEY-VCH}

In this work, a hydrogen molybdenum bronze $\left(\mathrm{H}_{0.11} \mathrm{MoO}_{3}\right)$ is in-situ-converted to molybdenum oxide $\left(\mathrm{MoO}_{2.94}\right)$ on top of ITO and explored as a hole transport layer in vacuum-deposited perovskite solar cells. A power conversion efficiency of $17.3 \%$ (average) is achieved for an ITO/MoO ${ }_{2.94} / \mathrm{TaTm} / \mathrm{MAPI} / \mathrm{C}_{60} / \mathrm{BCP} / \mathrm{Ag}$ optimal device, with great stability and reproducibility.

\section{Perovskite solar cell}

K. P. S. Zanoni*, D. Pérez-del-Rey, C. Dreessen, $M^{a}$ A. Hernández-Fenollosa, A. S. S. de Camargo, M. Sessolo, P. P. Boix*, H. J. Bolink

\section{Use of Hydrogen Molybdenum Bronze in Vacuum-Deposited Perovskite Solar Cells}

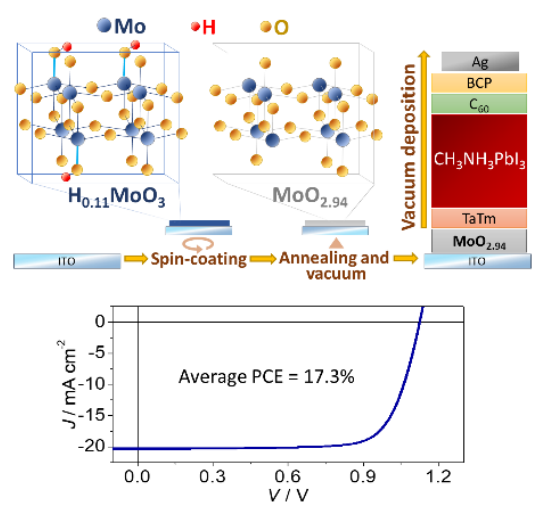

